1

2

3

4

5

6

October 20, 2014

\title{
SEVERITY GRADING OF CHRONIC OBSTRUCTIVE PULMONARY DISEASE: THE CONFOUNDING EFFECT OF PHENOTYPE AND THORACIC GAS COMPRESSION
}

Riccardo Pellegrino, $\mathrm{MD}^{1}$, Emanuele Crimi, $\mathrm{MD}^{2}$, Alessandro Gobbi, $\mathrm{PhD}^{3}$, Roberto Torchio, $\mathrm{MD}^{4}$, Andrea Antonelli, $\mathrm{MD}^{1}$, Carlo Gulotta, $\mathrm{MD}^{5}$, Michele Baroffio, $\mathrm{PhD}^{2}$, Giuseppe Francesco Sferrazza Papa, $\mathrm{MD}^{6}$, Raffaele Dellacà, $\mathrm{PhD}^{3}$, Vito Brusasco, $\mathrm{MD}^{2}$.

From: ${ }^{1}$ Allergologia e Fisiopatologia Respiratoria, ASO S. Croce e Carle, 12100 Cuneo;

${ }^{2}$ Dipartimento di Medicina Interna e Specialità Mediche, Università di Genova, 16132 Genova;

${ }^{3}$ Dipartimento di Elettronica, Informazione e Bioingegneria, Politecnico di Milano, 20133 Milano;

${ }^{4}$ Laboratorio di Fisiopatologia Respiratoria e Centro Disturbi Respiratori nel Sonno, Ospedale S.

Luigi, Orbassano, 10043 Torino; ${ }^{5}$ Malattie Apparato Respiratorio, Ospedale S.Luigi, Orbassano, 10043 Torino; ${ }^{6}$ Unità Respiratoria, Ospedale San Paolo, Università degli Studi di Milano, 20133 Milano (Italy)

Address for correspondence: Riccardo Pellegrino, MD; Allergologia e Fisiopatologia Respiratoria; ASO S. Croce e Carle; 12100 Cuneo, Italy; Tel. +39 0171616755; Fax: +39 0171616798; E-mail: pellegrino.r@ospedale.cuneo.it

Key words: Forced expiratory volume in $1 \mathrm{~s}$, plethysmography, emphysema, chronic bronchitis.

Running title: COPD severity grading, phenotypes and gas compression

Total word count: text 3188 , abstract 220 . 


\section{ABSTRACT}

28 Current guidelines recommend severity of chronic obstructive pulmonary disease be graded

29

30

31

32

33

34 using forced expiratory volume in $1 \mathrm{~s}\left(\mathrm{FEV}_{1}\right)$. But this measurements is biased by thoracic gas compression depending on lung volume and airflow resistance. The aim of this study was to test the hypothesis that the effect of thoracic gas compression on $\mathrm{FEV}_{1}$ is greater in emphysema than chronic bronchitis due to larger lung volumes and this influences severity classification and prognosis. $\mathrm{FEV}_{1}$ was simultaneously measured by spirometry and body plethysmography $\left(\mathrm{FEV}_{1-}\right.$ pl) in 47 subjects with dominant emphysema and 51 with dominant chronic bronchitis. Subjects with dominant emphysema had larger lung volumes, lower diffusion capacity and lower $\mathrm{FEV}_{1}$ than those with dominant chronic bronchitis. However, $\mathrm{FEV}_{1-\mathrm{pl}}$, patient-centered variables (dyspnea, quality of life, exercise tolerance, exacerbation frequency), arterial blood gases, and respiratory impedance were not significantly different between groups. Using $\mathrm{FEV}_{1-\mathrm{pl}}$ instead of $\mathrm{FEV}_{1}$ shifted severity distribution towards less severe classes in dominant emphysema more than chronic bronchitis. The Body mass, Obstruction, Dyspnea, and Exercise (BODE) index was significantly higher in dominant emphysema than chronic bronchitis but this difference significantly decreased when $\mathrm{FEV}_{1-\mathrm{pl}}$ was substituted for $\mathrm{FEV}_{1}$. In conclusion, the $\mathrm{FEV}_{1}$ is biased by thoracic gas compression more in subjects with dominant emphysema than in those with chronic bronchitis. This variably and significantly affects the severity grading systems currently recommended. 


\section{INTRODUCTION}

Ever since the pioneering work of Tiffeneau (34), the forced expiratory volume in $1 \mathrm{~s}$ $\left(\mathrm{FEV}_{1}\right)$ has been used as the key measurement of lung function for both diagnosis and severity assessment of obstructive lung disorders. The underlying rationale is grounded on the concept that maximal expiratory flow and thus the $\mathrm{FEV}_{1}$ decreases in disease and this is the result of a variable combinations of decrease in lung elastic recoil, decrease in airway size at choke point, increase in resistance upstream from the flow limiting segment, and increased airway collapsibility downstream from this segment (17). However, this analysis does not consider that during forced expiration thoracic gas is compressed because the expiratory pressure is well in excess to that necessary to generate maximal flow (17). As a result of the large effort, lung volume and thus recoil will decrease. This will cause a decrease of driving pressure and transmural pressure at choke point, which can explain why the $\mathrm{FEV}_{1}$ is systematically less than that measured in body plethysmograph $\left(\mathrm{FEV}_{1-\mathrm{pl}}\right)$ by the amount of thoracic gas compression volume (TGCV) (21). Confirmatory evidence for this has been brought by Krowka et al. by showing that with decreasing expiratory effort TGCV to a minimal value the $\mathrm{FEV}_{1}$ becomes similar to $\mathrm{FEV}_{1-\mathrm{pl}}(21)$. In addition to the expiratory effort, airflow resistance and absolute lung volume crucially contribute to increase $\operatorname{TGCV}(17,18)$, and thus the difference between $\mathrm{FEV}_{1-\mathrm{pl}}$ and $\mathrm{FEV}_{1}(32,33)$.

Current international guidelines and strategy documents $(9,10,26,29,31,35)$ recommend severity of chronic obstructive pulmonary disease (COPD) be graded by the FEV 1 reduction below predicted values, irrespective of the underlying mechanisms. This is justified by the fact that expiratory flow limitation in COPD may be equally due to intrinsic airway narrowing, the characteristic feature of chronic bronchitis, or reduced lung elastic recoil, the characteristic feature of emphysema (6). However, emphysema is also characterized by an increase in absolute lung volume, thus exposing a larger amount of thoracic gas to compression during a forced expiratory maneuver. Therefore, it can be hypothesized that, for a given airway 
resistance, the $\mathrm{FEV}_{1}$ overestimates the magnitude of airflow limitation in subjects with dominant emphysema compared with those with dominant bronchitis and this may confound severity classification and prognosis $(9,10,26,29,31,35)$.

This study was designed to test this hypothesis by comparing $\mathrm{FEV}_{1}$ and compression-free $\mathrm{FEV}_{1}$ measured in a body plethysmograph $\left(\mathrm{FEV}_{1-\mathrm{pl}}\right)$ with absolute lung volumes, respiratory impedance, diffusion capacity, arterial gas tensions, dyspnea, quality of life, exercise performance, and exacerbations rate in two groups of COPD subjects with either dominant emphysema or chronic bronchitis. The impact of thoracic gas compression on different severity classification systems was estimated by substituting $\mathrm{FEV}_{1-\mathrm{pl}}$ for $\mathrm{FEV}_{1}$.

\section{METHODS}

Subjects

The study included 98 subjects with a clinical diagnosis of COPD (31) and not completely reversible airflow obstruction documented by a post-bronchodilator $\mathrm{FEV}_{1}$ to vital capacity $(\mathrm{VC})$ ratio $\left(\mathrm{FEV}_{1} / \mathrm{VC}\right)$ below the lower limit of normality and total lung capacity within or above the limits of normality (27). Severity of disease was graded using the criteria proposed by the Global Initiative for Obstructive Lung Disease (GOLD) in 2007 (31) and 2013 (35), and the Body mass index, Obstruction, Dyspnea, and Exercise capacity (BODE) index (8). All subjects were required to be in stable clinical conditions and not to have suffered from respiratory exacerbations in the previous four weeks. Subjects with a history suggestive of bronchial asthma were excluded. Prior to each study session, long-acting $\beta_{2}$-agonists (salmeterol or formoterol) were suspended for at least $12 \mathrm{~h}$ and tiotropium for $24 \mathrm{~h}$. No subject was taking indacaterol or muscarinic antagonists other than tiotropium. The study protocol was approved by the S. Luigi Hospital Ethics Committee (Orbassano, Torino) (number 103, 23-06-2006) and written informed consent was obtained from each subject prior to the study. 
Study design

On a pre-study day, subjects underwent clinical examination, evaluation for inclusion and exclusion criteria, and assessment of clinical stability.

On a first study day, a 3-mL arterial blood sample was drawn for $\mathrm{PaO}_{2}$ and $\mathrm{PaCO}_{2}$ measurements (ABL 520, Radiometer, Copenhagen, Denmark). Then, Medical Research Council (MRC) questionnaire for dyspnea and Saint George's Respiratory Questionnaire (SGRQ) were administered. A chest X-ray with posterior-anterior and right-left projections was taken if not available over the previous 6 months. Exacerbations were defined according to Vestbo et al. (35) and their number recorded over the last two years.

On a second study day, the patients underwent full lung function examination. Spirometry and absolute lung volumes were obtained with the subjects sitting in a body plethysmograph (Autobox, SensorMedics Inc., CA, USA). After at least four regular breaths, thoracic gas volume was measured with the subject panting against a closed shutter at a frequency slightly $<1 \mathrm{~Hz}$ with his/her cheeks supported by hands. Then, the shutter was opened and the subject took a full deep breath to total lung capacity (TLC) before forcefully expiring to residual volume (RV) for at least 6 s. This maneuver allowed calculating functional residual capacity (FRC) from thoracic gas volume corrected for any difference between the volume at which the shutter was closed and the average end-expiratory tidal volume of the four preceding regular breaths, TLC, RV, vital capacity (VC), and $\mathrm{FEV}_{1}$. Compression-free $\mathrm{FEV}_{1}$ was simultaneously obtained by plotting mouth flow against change in plethysmographic volume to measure $\mathrm{FEV}_{1-\mathrm{pl}}$ (Figure 1). Three sets of technically acceptable maneuvers were obtained and appropriately selected values $(24,36)$ were retained for analysis. Respiratory impedance was measured by a forced-oscillation technique (FOT) previously described $(12,15)$. Sinusoidal pressure oscillations $\left(5-\mathrm{Hz}, \sim 2-\mathrm{cmH}_{2} \mathrm{O}\right.$ peak-to-peak $)$ were generated by a loudspeaker with a diameter of 16-cm (model CW161N, Ciare, Italy) and applied at the mouth. The loudspeaker was mounted in a rigid plastic box and connected in parallel to a mesh pneumotachograph and mouthpiece on one side and to a low-resistance high-inertance tube (overall 
125 load at tidal breathing frequency, $0.98 \mathrm{~cm} \mathrm{H} \mathrm{H}_{2} \mathrm{O} \cdot \mathrm{L} \cdot \mathrm{s}^{-1}$ ) on the other side. Airway opening pressure

126 and flow were measured by piezoresistive transducers (DCXL10DS and DCXL01DS

127 Sensortechnics, Germany, respectively) and sampled at $200 \mathrm{~Hz}$. A $15-\mathrm{L} \cdot \mathrm{min}^{-1}$ bias flow of air 128 generated by an air pump (CMP08, 3A Health Care, Italy) was used to reduce dead space to about $12935 \mathrm{~mL}$. Respiratory resistance and reactance were computed by a least squares algorithm $(19,20)$ at $1305 \mathrm{~Hz}\left(\mathrm{R}_{5}\right.$ and $\mathrm{X}_{5}$, respectively) and $19 \mathrm{~Hz}\left(\mathrm{R}_{19}\right.$ and $\mathrm{X}_{19}$, respectively). Artifacts due to glottis closure 131 or expiratory airflow limitation were avoided by discarding breaths showing any of the following: i) 132 tidal volume $<0.1 \mathrm{~L}$ or $>2.0 \mathrm{~L}$, ii) difference between measured flow oscillation and ideal sine wave 133 with the same Fourier coefficients $>0.2$ (23), and iii) ratio of minimum to average $X>3.5$ (14).

134 Measurements were taken during two sets of maneuvers, each consisting of 2-min tidal breathing on 135 which mean $\mathrm{R}_{5}, \mathrm{R}_{19}, \mathrm{R}_{5-19}$, and $\mathrm{X}_{5}$ were retained for analysis. Of the main function parameters of 136 the FOT, $\mathrm{R}_{5}$ was taken as an index of overall airflow resistance of the respiratory system, $\mathrm{R}_{19}$ as an 137 index of central airways resistance, $\mathrm{R}_{5-19}$ as an index of serial or peripheral heterogeneous 138 ventilation and $\mathrm{X}_{5}$ as an index of capacitative component of the respiratory system. Tidal volume $139\left(\mathrm{~V}_{\mathrm{T}}\right)$, breathing frequency $(\mathrm{BF})$, and minute ventilation $\left(\dot{\mathrm{V}}_{\mathrm{E}}\right)$ were averaged over the same tidal 140 breaths used for FOT data collection. Single-breath $\mathrm{D}_{\mathrm{L}} \mathrm{CO}$ was measured following the 141 recommendation of the American Thoracic Society and European Respiratory Society (22) and 142 6MWD according to ATS guidelines (3). Predicted values for the spirometry and lung volumes were from Quanjer et al. (30). To 144 estimate predicted $\mathrm{FEV}_{1-\mathrm{pl}}$, the predicted $\mathrm{FEV}_{1}$ was increased by $4.5 \%$. This was the difference 145 between $\mathrm{FEV}_{1-\mathrm{pl}}$ and $\mathrm{FEV}_{1}$ observed in a group of 81 healthy subjects ( 31 females and 50 males, 146 aged $46 \pm 12 \mathrm{yr}$., with a BMI of $24 \pm 3 \mathrm{~kg} \cdot \mathrm{m}^{-2}$ ), independent of anthropometric data. Predicted values 147 for $\mathrm{D}_{\mathrm{L}} \mathrm{CO}$ were from Cotes et al. (11) and those of 6MWD from the ATS guidelines (3). 
At the end of studies, subjects were grouped depending on dominant phenotype, i.e.,

151

152

153

154 chronic bronchitis or emphysema (Table 1), based on the clinical and radiological score (CRS) proposed by Pistolesi et al. (28) This score was obtained by a multivariate model with the following independent variables: sputum purulence, adventitious chest sounds, chest hyperresonance, $\mathrm{FEV}_{1} / \mathrm{VC}$, and radiographic signs of increased vascular markings, bronchial wall thickening, reduced lung density, increased lung volume. A score $>0.56$ was taken as suggestive of dominant emphysema and $\leq 0.56$ of dominant chronic bronchitis (28).

Differences in baseline characteristics between groups were assessed for statistical significance by unpaired t-test. Between-within group data were tested by a mixed repeatedmeasure ANOVA. Categorical data were compared by Fischer exact test with Freeman-Halton's extension for $2 \times 4$ contingency tables when appropriate. Values of $p<0.05$ were considered statistically significant. Data are presented as mean \pm standard deviation. Statistical analyses were done by StatSoft Statistica and VassarStats website packages.

\section{RESULTS}

The two groups were well matched for anthropometric characteristics except than for body mass index (BMI), which was slightly lower in dominant-emphysema group (Table 1). Subjects with dominant emphysema had significantly lower $\mathrm{D}_{\mathrm{L}} \mathrm{CO}, \mathrm{D}_{\mathrm{L}} \mathrm{CO} / \mathrm{V}_{\mathrm{A}}$, and $\mathrm{FEV}_{1}$ and significantly larger TLC, FRC and RV than subjects with dominant chronic bronchitis (Table 1). However, neither $\mathrm{FEV}_{1-\mathrm{pl}}$ nor $\mathrm{FVC}$, nor impedance components, i.e., respiratory resistance and reactance, were significantly different between groups either before or after albuterol administration (Table 2). Analysis of the main quality control indexes such as back-extrapolation volume, time to peak flow, and tidal breathing pattern, viz., breathing frequency and minute ventilation $\left(\dot{\mathrm{V}}_{\mathrm{E}}\right)$ did not reveal significant differences between groups (Table 3). Moreover, there were no significant differences between groups concerning arterial blood gases, degree of dyspnea (MRC score), quality of life (SGRQ), physical performance (6MWD), and number of 
exacerbations per year (Table 4). Post- bronchodilator $\mathrm{FEV}_{1-\mathrm{pl}}$ was significantly larger than $\mathrm{FEV}_{1}$ $(\mathrm{p}<0.0001)$ in both groups, but this difference was significantly larger in dominant emphysema than chronic bronchitis group $(\mathrm{p}=0.0026)$. Consistent with these data, post-bronchodilator $\mathrm{FEV}_{1-}$ pl was not significantly different between dominant emphysema and chronic bronchitis groups (Table 2 and Figure 2).

Grading the severity of disease using old GOLD score by $\mathrm{FEV}_{1}$ led to a significant $(p=0.0115)$ excess of III-IV classes in dominant emphysema compared with chronic bronchitis group (Figure 3). By using $\mathrm{FEV}_{1-\mathrm{pl}}$ the class distribution was not significantly different between groups $(\mathrm{p}=0.3162)$ and the proportion of subjects shifting from III-IV to I-II classes was significantly $(p=0.0348)$ larger in dominant emphysema (16 out of 47$)$ than chronic bronchitis $(8$ out of 51) group. With the new GOLD grading system, the distribution of A-B and C-D stages was insignificantly different between groups using either $\mathrm{FEV}_{1}$ or $\mathrm{FEV}_{1 \text {-pl }}$.

The BODE score was significantly higher in subjects with dominant emphysema than those with chronic bronchitis using either spirometric $\mathrm{FEV}_{1}$ or $\mathrm{FEV}_{1-\mathrm{pl}}(\mathrm{p}=0.0079)$ (Figure 4), but the difference between groups became significantly less (interaction $\mathrm{p}=0.0168$ ) when $\mathrm{FEV}_{1-\mathrm{pl}}$ was substituted for $\mathrm{FEV}_{1}$. There was a prevalence of more severe BODE stages in dominant emphysema than chronic bronchitis group using either $\operatorname{FEV}_{1}(p=0.0111)$ or $\operatorname{FEV}_{1-p l}(p=0.0324)$. But the proportion of subjects shifting from III-IV to I-II stages using FEV $_{1-p l}$ instead of $\mathrm{FEV}_{1}$ was significantly $(\mathrm{p}=0.0180)$ larger in dominant emphysema ( 9 out of 47$)$ than chronic bronchitis (2 out of 51) group (Figure 5).

\section{DISCUSSION}

The main results of the present study are the following: 1) $\mathrm{FEV}_{1}$ was significantly less in subjects with dominant emphysema than those with chronic bronchitis, 2) FEV 1-pl, respiratory impedance parameters, arterial blood gases, and patient-centered variables, namely, dyspnea, quality of life, physical performance, and number of exacerbations/yr were similar between 
202

203

204

205

206

207

208

209

210

211

212

213

214

215

216

217

218

219

220

221

222

223

224

225

226

groups, 3) using $\mathrm{FEV}_{1-\mathrm{pl}}$ instead of $\mathrm{FEV}_{1}$ resulted in a significant shift towards lower severity classes more in dominant emphysema than chronic bronchitis group, and 4) BODE index was significantly higher in dominant emphysema than chronic bronchitis group using $\mathrm{FEV}_{1}$ but this difference was significantly attenuated by using FEV $_{1-p l}$.

\section{Interpretation of results}

The use of $\mathrm{FEV}_{1}$ as an index of severity of pulmonary disorders stems from the paper by Fletcher and Peto (13) suggesting that this parameter may decline with age at the faster rate in smokers than in healthy subjects. Further longitudinal studies in COPD showed indeed that FEV 1 is a predictor of either respiratory or all-cause mortality $(4,35)$. Therefore, current guidelines and strategy documents have recommended the use of $\mathrm{FEV}_{1}$ to stratify COPD subjects by severity ( 9 , $10,26,29,31,35)$. However, the observation that $\mathrm{FEV}_{1}$ is weakly correlated with patientcentered variables, such as dyspnea (37), exercise tolerance (5), and health-related quality of life (16), has prompted the introduction of composite classification criteria $(8,35)$. Furthermore, it has been recently proposed that a classification based not only on severity but also on phenotype may represent a step forward for personalized treatment of COPD patients (25).

In whatever stratification system, the severity of lung function abnormality has been graded based on the $\operatorname{FEV}_{1}(1,2,9,25,26,27,29,31,35)$. In theory, this is justified by the fact that the $\mathrm{FEV}_{1}$ reflects expiratory flow limitation, which is a marker of the disease. Yet, forced expiratory flow and thus $\mathrm{FEV}_{1}$ are determined by different yet indistinguishable mechanisms, such as lung elastic recoil, resistance upstream from the flow limiting segment, and airway size and stiffness (17). In addition, during a forced expiratory maneuver, part of intrathoracic gas is compressed as a result of an excess in alveolar pressure with respect to critical pressure necessary to generate maximal flow $(17,18,21)$, thus causing the $\mathrm{FEV}_{1}$ measured at the mouth to be lower than the simultaneous change in chest wall volume measurable by a body 
plethysmograph. This difference is small in healthy subjects but it may become large in disease as a result of the increase in airflow resistance, or lung volume, or both $(21,32,33)$.

The present study is the first one in which the impact of thoracic gas compression on the severity classification of COPD has been examined in relation to dominant phenotypes. The findings show that $\mathrm{FEV}_{1}$ measured at the mouth was consistently lower in subjects with dominant emphysema with respect to those with dominant chronic bronchitis despite similar patient-centered variables, blood gas data, and indexes of respiratory mechanics measured during tidal breathing by FOT. The fact that the two phenotypes did not differ for $\mathrm{R}_{5}, \mathrm{R}_{19}, \mathrm{R}_{5-19}$ and $\mathrm{X}_{5}$, which are very sensitive indexes of airway mechanics and $\mathrm{FEV}_{1-\mathrm{pl}}$ strongly suggests that the more severe reduction of $\mathrm{FEV}_{1}$ observed in emphysema than chronic bronchitis phenotype is not a reflection of greater degree of airflow obstruction but rather a greater amount of thoracic gas compression volume. Although such a difference of $\mathrm{FEV}_{1}$ could be due to different expiratory efforts, this possibility is presumably ruled out by the similarities of time to peak flow and back extrapolation volume between groups. More likely, the differences in $\mathrm{FEV}_{1}$ between phenotypes were due to larger lung volume in emphysema, as predicted on the ground of the wave-speed theory of expiratory flow limitation. During a forced expiration, alveolar pressure increases and gas is compressed within the lung, thus causing lung volume and lung elastic recoil to decrease. A reduction of elastic recoil pressure will result in a reduction of driving pressure and transmural pressure at choke point, which can explain why $\mathrm{FEV}_{1}$ was systematically less than $\mathrm{FEV}_{1 \text {-p1 }}$. Being the amount of thoracic gas compression larger in larger than smaller lungs, for a given pressure and airflow resistance, this would explain why the difference between $\mathrm{FEV}_{1-\mathrm{pl}}$ and $\mathrm{FEV}_{1}$ was greater in dominant emphysema than chronic bronchitis group.

The present results are in keeping with previous studies. Krowka et al (21) found that decreasing expiratory effort was associated with a tendency of $\mathrm{FEV}_{1}$ to increase above the threshold of natural variability and suggested that this negative effort-dependence of forced expiratory flow may confound the interpretation of spirometry and bronchomotor tests if 
253

maneuvers are performed with different efforts. Sharafkhaneh et al. (32) measured simultaneously $\mathrm{FEV}_{1}$ and $\mathrm{FEV}_{1-\mathrm{pl}}$ in $\mathrm{COPD}$ subjects undergoing lung volume reduction surgery and found that about $40 \%$ of the increase in $\mathrm{FEV}_{1}$ after surgery was explained by the reduction in the amount of thoracic gas compression.

\section{Limitations of the study}

The present study has limitations. First, no quantitative assessment of emphysema was made by high-resolution computed-tomography (HRCT). However, the clinical and radiological score model was validated against HRCT (28) and, although a zone of overlap may be present, the two groups of this study exhibited values quite far from the cutoff value. Moreover, there were significant differences between groups in TLC and $\mathrm{D}_{\mathrm{L}} \mathrm{CO}$, which are strong correlates of anatomical emphysema (7) that were not included in the model. Thus, it seems justified to assume that the method used for grouping subjects with dominant emphysema or chronic bronchitis was adequate for the purposes of this study. Second, predicting equations for FEV $\mathrm{F}_{1-\mathrm{pl}}$ are not available and therefore predicted values were obtained by increasing predicted $\mathrm{FEV}_{1}$ by a fixed amount determined in a group of healthy subjects. This might have determined systematic over- or under-estimation of severity in both groups, but this would unlikely explain differences between groups. Third, because of its cross-sectional nature, the study cannot provide direct information on the prognostic role of different pulmonary function tests. Nevertheless, the present data show that thoracic gas compression could potentially affect BODE index, which has been proposed as a sensitive predictor of mortality.

\section{Clinical and therapeutic implications}

The results of the present study have practical implications owing to the use of severity grading for choice of treatment $(9,10,26,29,31,35)$ and prognosis $(8)$. Indeed, using $\mathrm{FEV}_{1-\mathrm{pl}}$ instead of $\mathrm{FEV}_{1}$ caused a shift from GOLD III-IV to GOLD I-II classes in a larger number of 
subjects with dominant emphysema than dominant chronic bronchitis. Were this classification used as a treatment guidance, more subjects with dominant emphysema would have received combined treatment with inhaled steroids than subjects with dominant chronic bronchitis even if clinical variables and airway mechanical conditions were not dissimilar. With the 2013 GOLD classification based on the $\mathrm{FEV}_{1}$, dyspnea, and exacerbation number, using $\mathrm{FEV}_{1 \text {-pl }}$ instead of $\mathrm{FEV}_{1}$ did not lead to significant differences between subjects with dominant chronic bronchitis or emphysema. We speculate that this is because of a relatively minor role for lung function with respect to dyspnea and exacerbations in this multidimensional grading system. The BODE index albeit multidimensional was affected by gas compression more in dominant emphysema than chronic bronchitis group. Using $\mathrm{FEV}_{1-\mathrm{pl}}$ instead $\mathrm{FEV}_{1}$ the difference between dominant emphysema and chronic bronchitis group was significantly reduced but still significant, presumably because of the lower BMI in dominant emphysema group. Indeed, when a score including $\mathrm{FEV}_{1-\mathrm{pl}}$, MRC and $6 \mathrm{MWD}$ but not BMI was calculated there was no difference between dominant emphysema and chronic bronchitis group $(\mathrm{p}=0.3249)$.

\section{Conclusions}

The present study challenges the use of $\mathrm{FEV}_{1}$ as the sole lung function parameter for severity grading in COPD, because of its dependence on dominant phenotype.

Assuming that lung function measurements are still needed to confirm objectively the clinical diagnosis COPD, the practical question is which tests are more adequate than spirometric $\mathrm{FEV}_{1}$ to reflect COPD severity. An answer to this question will require longitudinal studies comparing the predicting value of different lung function tests on clinical outcomes in relation to the major phenotypes of this complex disease. These should include not only the classical measurements of lung volumes and $\mathrm{D}_{\mathrm{L}} \mathrm{CO}$, but also tests that are independent of thoracic gas compression and sensitive to airway caliber and ventilation heterogeneity. 


\section{REFERENCES}

1. American Thoracic Society. Standardization of spirometry: 1994 update. Am J Respir Crit Care Med 152: 1107-1136, 1995.

2. Anthonisen NR, Wright EC, Hodgkin JE. Prognosis in chronic obstructive pulmonary disease. Am Rev Respir Dis 133: 14-20, 1986.

3. ATS Statement: guidelines for the six-minute walk test. Am J Respir Crit Care Med 166: 111-117, 2002.

4. Bang KM, Gergen PJ, Kramer R, Cohen B. The effect of pulmonary impairment on all-cause mortality in a national cohort. Chest 103: 536-540, 1993.

5. Bauerle O, Chrusch CA, Younes M. Mechanisms by which COPD affects exercise tolerance. Am J Respir Crit Care Med 157: 57-68, 1998.

6. Brusasco V, Martinez F. Chronic obstructive pulmonary disease. Compr Physiol. (January 2014) doi: 10.1002/cphy.c110037.2014.

7. Burrows B, Fletcher CM, Heard BE, Jones NL, Wootliff JS. The emphysematous and bronchial types of chronic airways obstruction. A clinico pathological study of patients in London and Chicago. Lancet 1: 830-835, 1966.

8. Celli BR, Cote CG, Marin JM, Casanova C, Montes de Oca M, Mendez RA, Pinto Plata V, Cabral HJ. The body-mass index, airflow obstruction, dyspnea, and exercise capacity index in chronic obstructive pulmonary disease. $N$ Engl J Med 350: 1005-1012, 2004.

9. Celli BR, MacNee W. ATS/ERS Task Force. Standards for the diagnosis and treatment of patients with COPD: a summary of the ATS/ERS position paper. Eur Respir $J$ 23: 932-946, 2004.

10. Chronic obstructive pulmonary disease. National clinical guideline on management of chronic obstructive pulmonary disease in adults in primary and secondary care. National Collaborating Centre for Chronic Conditions. Thorax 59, suppl. 1: 1-232, 2004. 
11. Cotes JE, Chinn DJ, Quanjer PhH, Roca J, Yearnault J-C. Standardization of the measurement of transfer factor (diffusing capacity). Eur Respir J 6:41-52, 1993.

12. Dellacà RL, Pompilio PP, Walker PP, Duffy N, Pedotti A, Calverley PM. Effect of bronchodilation on expiratory flow limitation and resting lung mechanics in COPD. Eur Respir J33: 1329-1337, 2009.

13. Fletcher C, Peto R. The natural history of chronic airflow obstruction. $\mathrm{Br} M e d \mathrm{~J}$ 1: 1645-1648, 1977.

14. Gobbi A, Milesi I, Govoni L, Pedotti A, Dellacà RL. A new telemedicine system for the home monitoring of lung function in patients with obstructive respiratory diseases. IEEE: International Conference on eHealth, Telemedicine, and Social Medicine, (eTELEMED’09): $117-122 ; 2009$.

15. Gobbi A, Pellegrino R, Gulotta C, Antonelli A, Pompilio P, Crimi C, Torchio R, Dutto L, Parola P, Dellacà RL, Brusasco V. Short-term variability of respiratory impedance and effect of deep breath in asthmatic and healthy subjects with airway smooth muscle activation and unloading. J Appl Physiol 115: 708-715, 2013.

16. Hajiro T, Nishimura K, Tsukino M, Ikeda A, Koyama H, Izumi T. Comparison of discriminative properties among disease-specific questionnaires for measuring healthrelated quality of life in patients with chronic obstructive pulmonary disease. Am J Respir Crit Care Med 157: 785-790,1998.

17. Hyatt RE. Forced expiration. Handbook of Physiology. The Respiratory System. Mechanics of Breathing. Bethesda, MD: Am Physiol Soc, sect 3 Vol. III, part 1: 295-314, 1986.

18. Ingram RH Jr, Schilder DP. Effect of thoracic gas compression on the flow-volume curve of the forced vital capacity. Am Rev Respir Dis 94: 56-63, 1966. 
19. Kaczka DW, Barnas GM, Suki B, Lutchen KR. Assessment of time-domain analyses for estimation of low-frequency respiratory mechanical properties and impedance spectra. Ann Biomed Eng 23: 135-151, 1995.

20. Kaczka DW, Ingenito EP, Lutchen KR. Technique to determine inspiratory impedance during mechanical ventilation: implication for flow limited patients. Ann Biomed Eng 27: 340-355, 1999.

21. Krowka MJ, Enright PL, Rodarte JR, Hyatt RE. Effect of effort on measurement of forced expiratory volume in one second. Am Rev Respir Dis; 136: 829-833, 1987.

22. MacIntyre N, Crapo R, Viegi G, Johnson D, van der Grinten CPM, Brusasco V, Burgos F, Casaburi R, Coates A, Enright P, Gustafsson P, Hankinson J, Jensen R, McKay R, Miller MR, Navajas D, Pedersen OF, Pellegrino R, Wanger J. Standardization of the single breath determination of carbon monoxide uptake in the lung. Eur Respir J 26: 720-735, 2005.

23. Marchal F, Schweitzer C, Demoulin B, Chone C, Peslin R. Filtering artifacts in measurements of forced oscillation respiratory impedance in young children. Physiol Meas 25: 1153-1166, 2004.

24. Miller M, Hankinson J, Brusasco V, Burgos F, Casaburi R, Coates A, Crapo R, Enright P, van der Grinten CPM, Gustafsson P, Jensen R, Johnson DC, MacIntyre N, McKay R, Navajas D, Pedersen OF, Pellegrino R, Viegi G, Wanger J. Standardization of spirometry. Eur Respir J 26:319-338, 2005.

25. Miravitlles M, Soler-Cataluña JJ, Calle M, Molina J, Almagro P, Quintano JA, Trigueros JA, Piñera P, Simón A, Riesco JA, Ancochea J, Soriano JB. A new approach to grading and treating COPD based on clinical phenotypes: summary of the Spanish COPD guidelines (GesEPOC). Prim Care Respir J 22: 117-121, 2013.

26. O'Donnell DE, Hernandez P, Kaplan A, Aaron S, Bourbeau J, Marciniuk D, Balter M, Ford G, Gervais A, Lacasse Y, Maltais F, Road J, Rocker G, Sin D, Sinuff T, 
Voduc N. Canadian Thoracic Society recommendations for management of chronic obstructive pulmonary disease - 2008 update - highlights for primary care. Can Resp J 15 Suppl A: 1A-8A, 2008.

27. Pellegrino R, Viegi G, Brusasco V, Crapo RO, Burgos F, Casaburi R, Coates A, van der Grinten CPM, Gustafsson P, Hankinson J, Jensen R, Johnson D, MacIntyre N, McKay N, Miller MR, Navajas D, Pedersen OF, Wanger J. Interpretative strategies for lung function tests. Official statement of the American Thoracic Society and the European Respiratory Society. Eur Respir J 26: 948-968, 2005.

28. Pistolesi M, Camiciottoli G, Paoletti M, Marmai C, Lavorini F, Meoni E, Marchesi C, Giuntini C. Identification of a predominant COPD phenotype in clinical practice. Respir Med 102: 367-376, 2008.

29. Qaseem A, Wilt TJ, Weinberger SE, Hanania NA, Criner G, van der Molen T, Marciniuk DD, Denberg T, Schünemann H, Wedzicha W, MacDonald R, Shekelle P. American College of Physicians; American College of Chest Physicians; American Thoracic Society; European Respiratory Society. Diagnosis and management of stable chronic obstructive pulmonary disease: a clinical practice guideline update from the American College of Physicians, American College of Chest Physicians, American Thoracic Society, and European Respiratory Society. Ann Intern Med 155: 179-191, 2011.

30. Quanjer PhH, Tammeling GJ, Cotes JE, Pedersen OF, Peslin R, and Yernault JC. Standardized lung function testing. Eur Respir J 6: 1-40, 1993.

31. Rabe KF, Hurd S, Anzueto A, Barnes PJ, Buist SA, Calverley P, Fukuchi Y, Jenkins C, Rodriguez-Roisin R, van Weel C, Zielinski J. Global Initiative for Chronic Obstructive Lung Disease. Global strategy for the diagnosis, management, and prevention of chronic obstructive pulmonary disease: GOLD executive summary. Am $J$ Respir Crit Care Med 176: 532-555, 2007. 
32. Sharafkhaneh A, Goodnight-White S, Officer TM, Rodarte JR, Boriek AM. Altered thoracic gas compression contributes to improvement in spirometry with lung volume reduction surgery. Thorax 60: 288-292, 2005.

33. Sharafkhaneh A, Babb TG, Officer TM, Hanania NA, Sharafkhaneh H, Boriek AM. The confounding effects of thoracic gas compression on measurement of acute bronchodilator response. Am J Respir Crit Care Med 175: 330-335, 2007.

34. Tiffeneau R, Pinelli A. Air circulant et air captif dan l'esploration de la fonction ventilatrice pulmonaire. Paris Méd 37: 624-628, 1947.

35. Vestbo J, Hurd SS, Agustí AG, Jones PW, Vogelmeier C, Anzueto A, Barnes PJ, Fabbri LM, Martinez FJ, Nishimura M, Stockley RA, Sin DD, Rodriguez-Roisin R. Global strategy for the diagnosis, management, and prevention of chronic obstructive pulmonary disease: GOLD executive summary. Am J Respir Crit Care Med 187: 347$365,2013$.

36. Wanger J, Clausen JC, Coates A, Pedersen OF, Brusasco OF,Burgos F, Casaburi R, Crapo R, Enright P, van der Grinten CPM, Gustafsson P, Hankinson J, Jensen R, Johnson D, MacIntyre N, McKay R, Miller MR, Navajas D, Pellegrino R, Viegi G. Standardization of the measurement of lung volumes. Eur Respir J 26: 511-522, 2005.

37. Wolkove N, Dajczman E, Colacone A, Kreisman H. The relationship between pulmonary function and dyspnea in obstructive lung disease. Chest 96:1247-1251, 1989. 


\section{FIGURE LEGENDS}

Figure 1. Representative flow-volume curves of a COPD subject with dominant emphysema. Flow is plotted against expired volume (dashed line) or plethysmographic volume (continuous line). Forced expiratory volume in $1 \mathrm{~s}$ measured at mouth $\left(\mathrm{FEV}_{1}\right)$ was $1.26 \mathrm{~L}$ and by plethysmography $\left(\mathrm{FEV}_{1-\mathrm{pl}}\right) 1.75 \mathrm{~L}$.

Figure 2. Post-bronchodilator $\mathrm{FEV}_{1-\mathrm{pl}}$ in subjects with dominant emphysema $(\mathrm{E}+, \mathrm{n}=47)$ or chronic bronchitis $(\mathrm{CB}+, \mathrm{n}=51) . \mathrm{E}+$ vs. $\mathrm{CB}+, \mathrm{p}=0.1081 ; \mathrm{FEV}_{1}$ vs. $\mathrm{FEV}_{1-\mathrm{pl}}, \mathrm{p}<0.0000$; interaction, $\mathrm{p}=0.0026$. This would indicate that gas compression significantly affected forced expiratory volume in both groups, but significantly more in $\mathrm{E}+$ than $\mathrm{CB}+$. Values are mean and standard deviation.

Figure 3. Effect of thoracic gas compression on severity classifications of subjects with dominant emphysema $(E+, n=47)$ or chronic bronchitis $(B C+, n=51)$ according to the 2007 GOLD criteria (left panel) and 2013 GOLD criteria (right panel). P values indicate significance of differences in categorical distributions between groups by using $\mathrm{FEV}_{1}$ or $\mathrm{FEV}_{1-\mathrm{p}}$.

Figure 4. Effect of thoracic gas compression on BODE score in subjects with dominant emphysema $(E+, n=47)$ or chronic bronchitis $(C B+, n=51) . E+$ vs. $C B+, p=0.0079 ; \mathrm{FEV}_{1}$ vs. $\mathrm{FEV}_{1-\mathrm{pl}}, \mathrm{p}<0.0000$; interaction, $\mathrm{p}=0.0168$. This would indicate that gas compression significantly affected forced expiratory volume in both groups, but significantly more in $\mathrm{E}+$ than $\mathrm{CB}+$. Values are presented as mean and standard deviation.

Figure 5. Effect of thoracic gas compression on distribution of BODE stages. P values indicate significance of differences in categorical distributions between groups. 


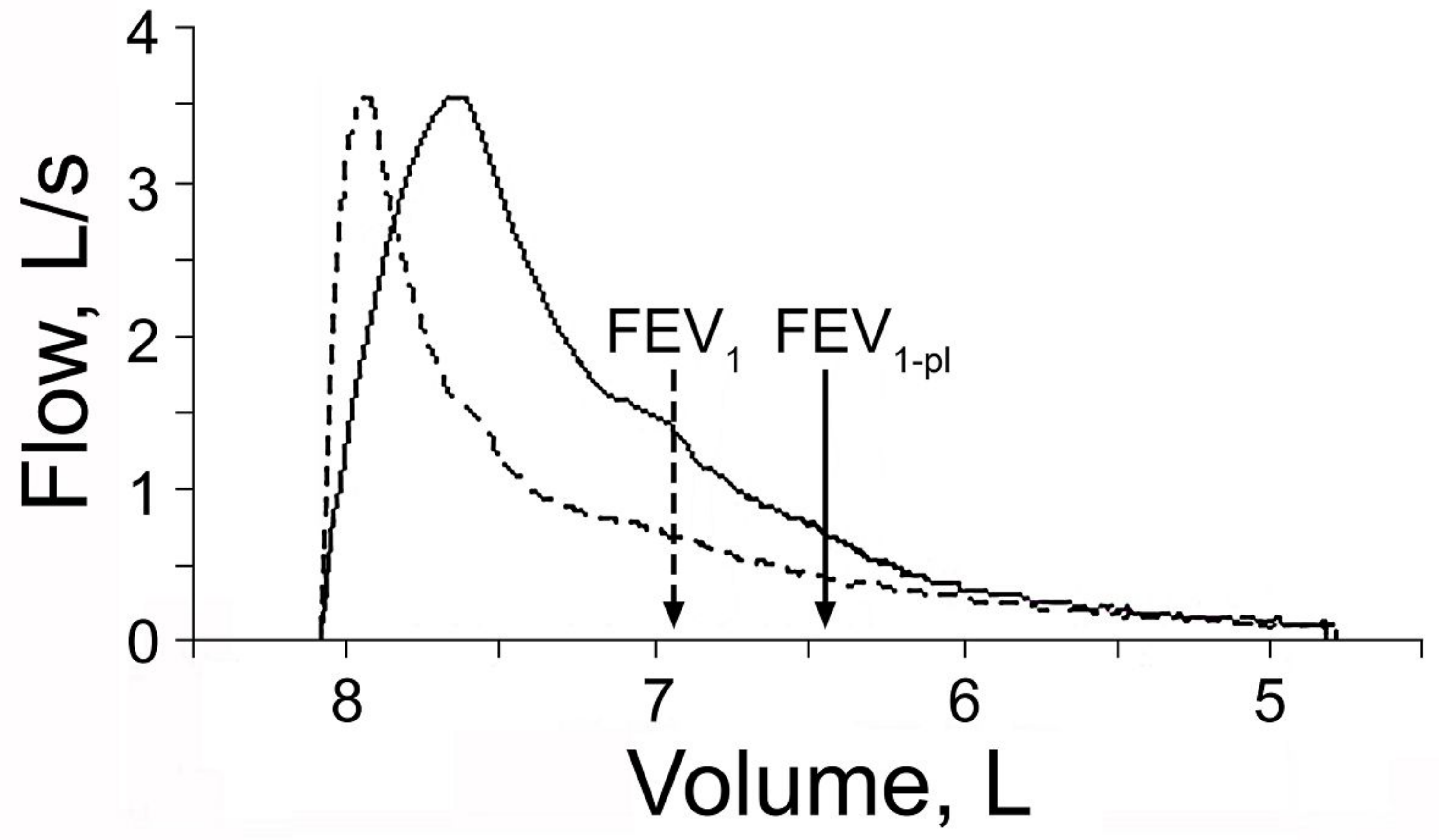




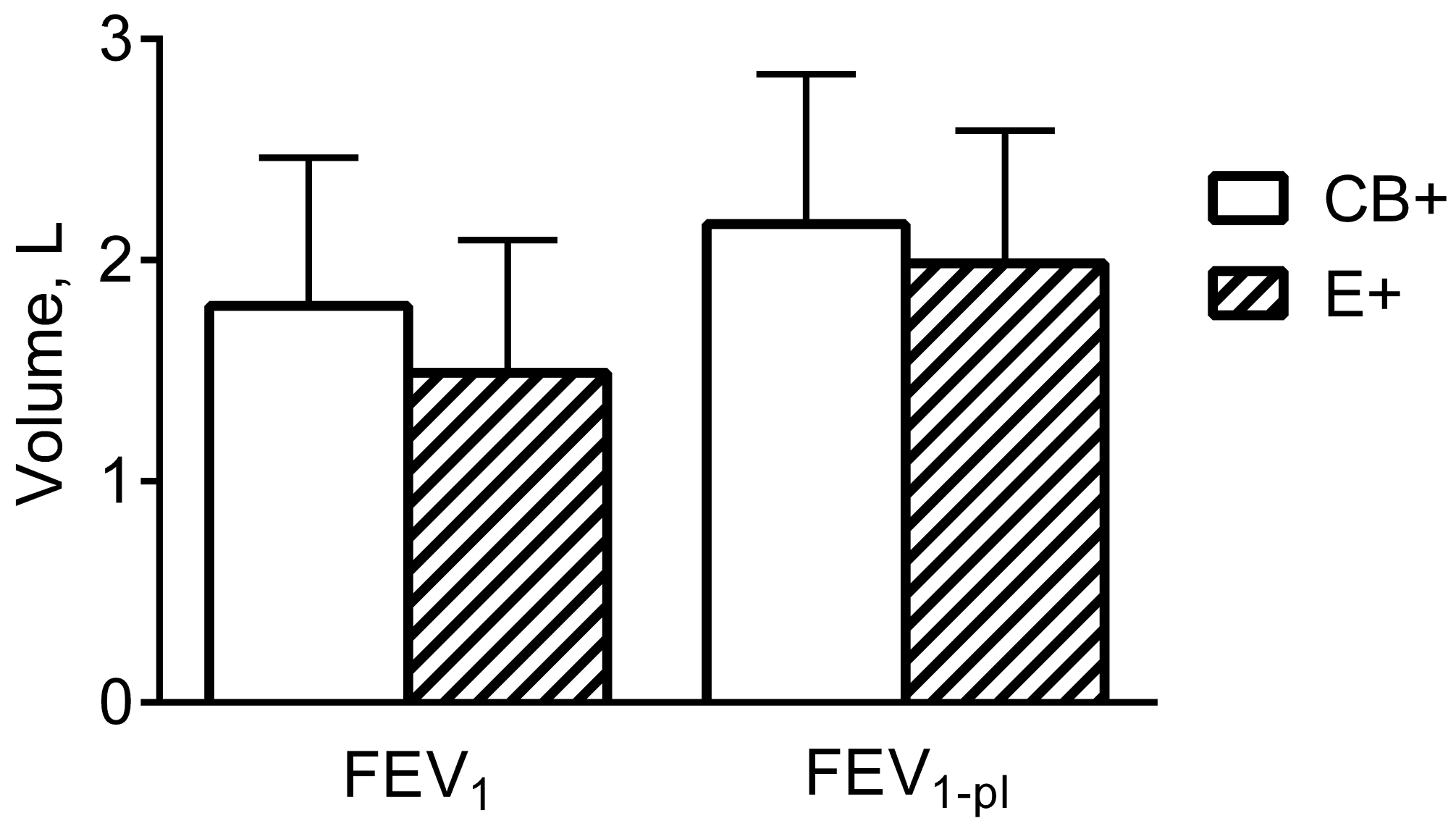



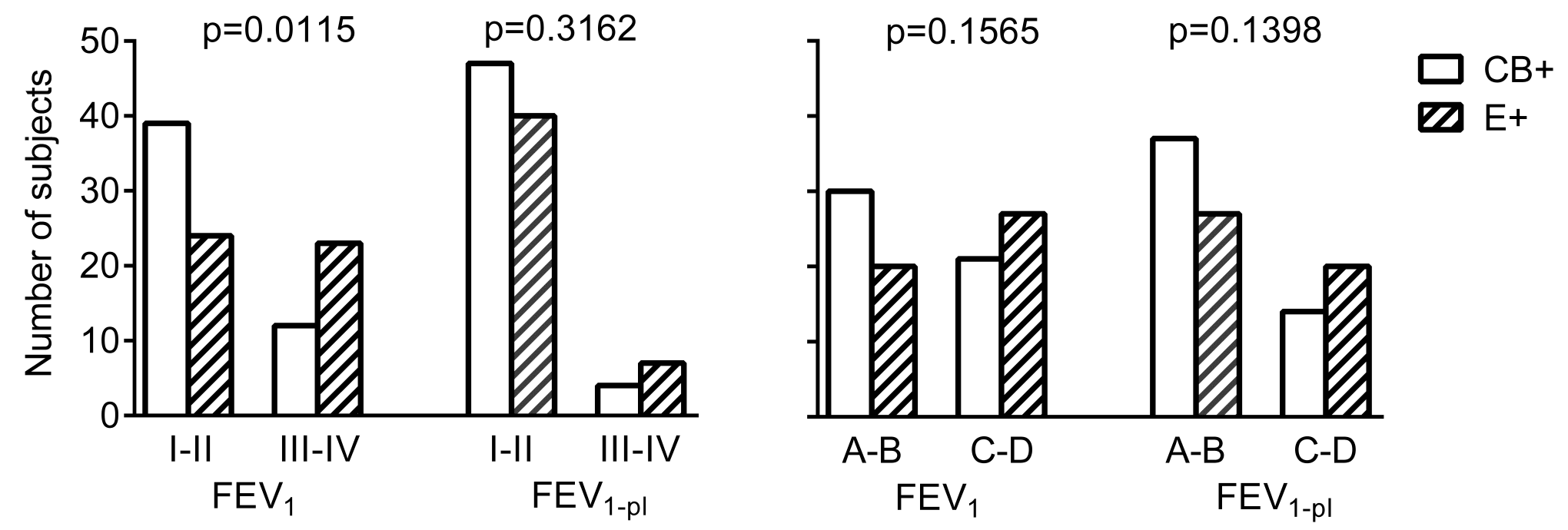


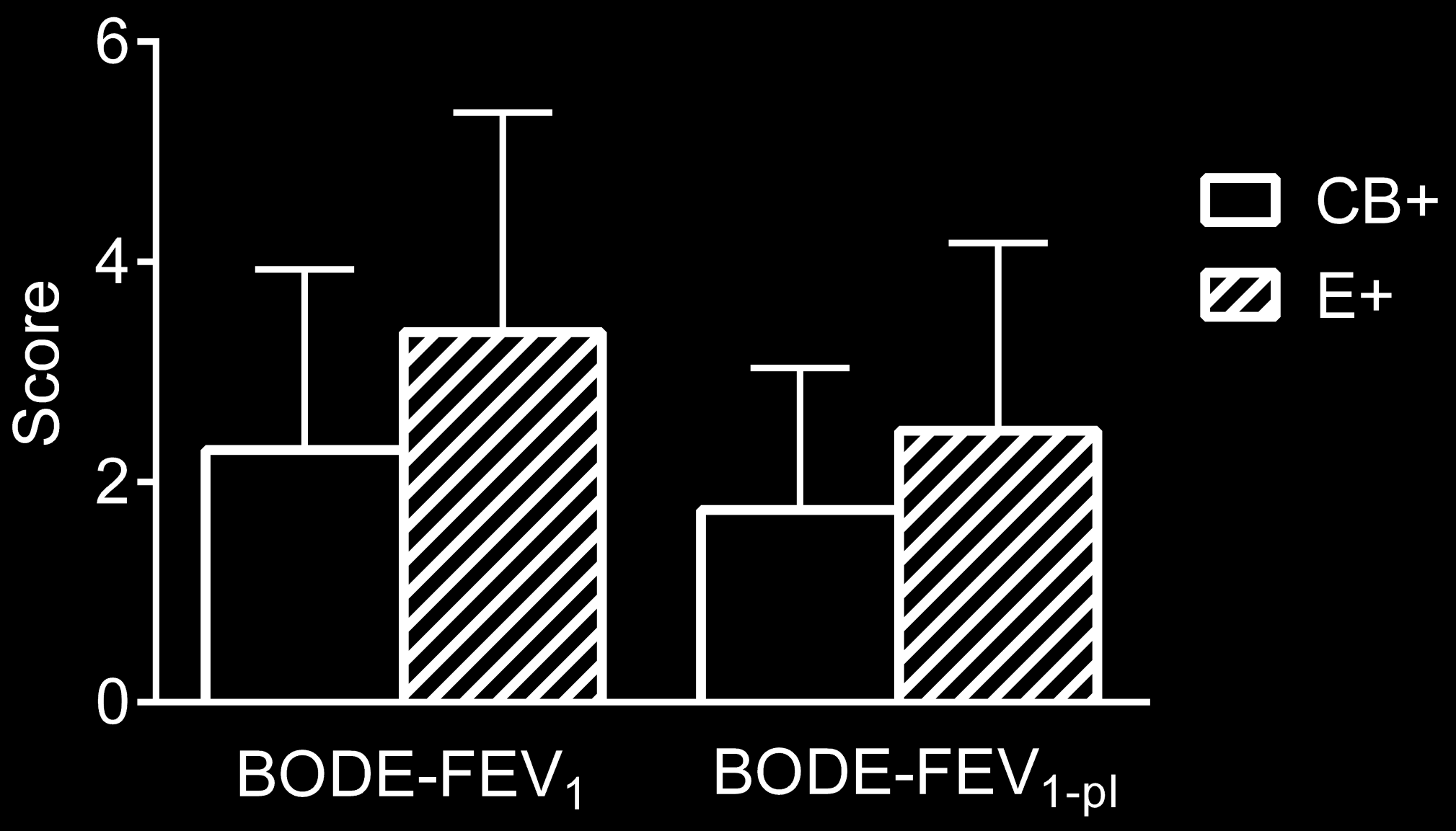



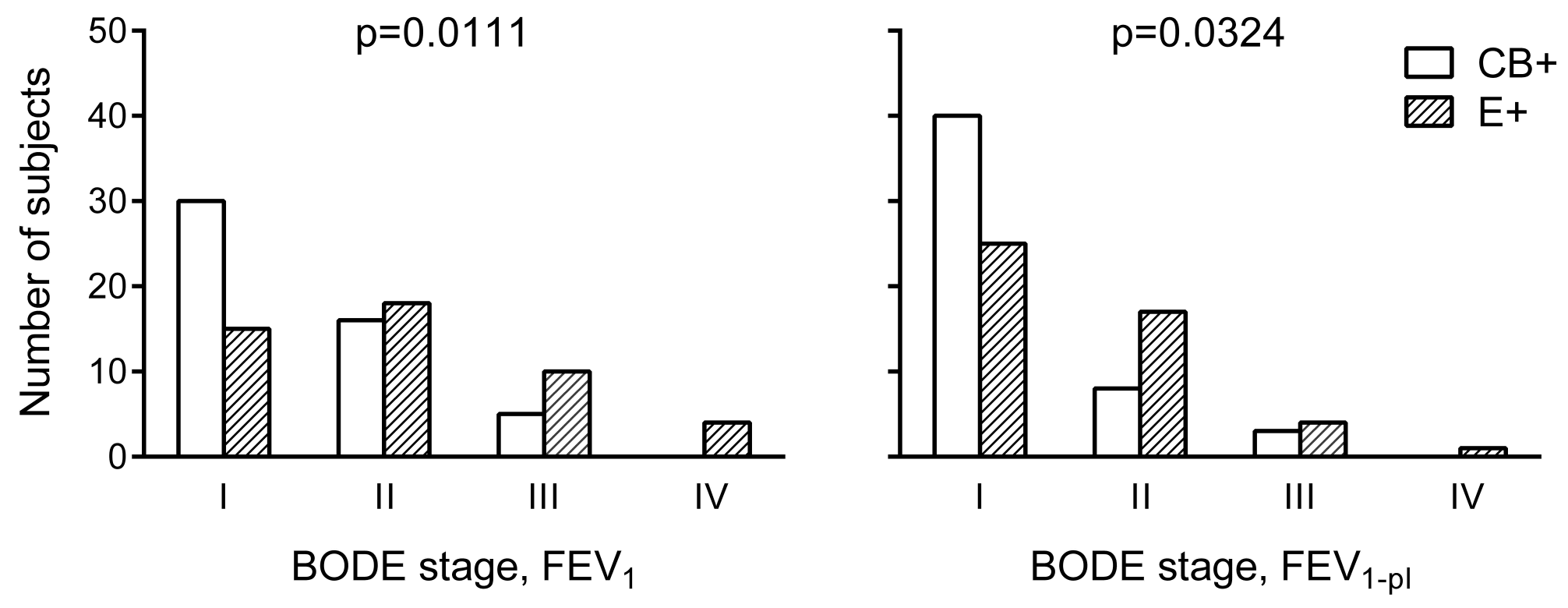
Table 1. Subjects' main anthropometric and lung function data.

\begin{tabular}{|l|c|c|c|}
\hline & $\begin{array}{c}\text { Dominant } \\
\text { Emphysema }\end{array}$ & $\begin{array}{c}\text { Dominant } \\
\text { Chronic Bronchitis }\end{array}$ & $\mathrm{P}$ \\
\hline Sex, M/F & $39 / 8$ & $42 / 9$ & 0.9349 \\
\hline Age, yr & $66 \pm 9$ & $67 \pm 8$ & 0.9080 \\
\hline Height, cm & $170 \pm 8$ & $168 \pm 8$ & 0.1020 \\
\hline Smoking habit, Yes/No & $46 / 1$ & $51 / 0$ & 0.9672 \\
\hline Pack-years & $45 \pm 18$ & $37 \pm 15$ & 0.0231 \\
\hline BMI, kg·m ${ }^{-2}$ & $23 \pm 4$ & $26 \pm 4$ & $<0.0001$ \\
\hline FEV,$\%$ of predicted & $48 \pm 17$ & $60 \pm 17$ & 0.0016 \\
\hline FEV $/$ VC, \% & $46 \pm 11$ & $55 \pm 9$ & $<0.0001$ \\
\hline FRC \% of predicted & $148 \pm 29$ & $131 \pm 29$ & 0.0046 \\
\hline RV, \% of predicted & $179 \pm 45$ & $155 \pm 40$ & 0.0067 \\
\hline TLC, \% of predicted & $115 \pm 14$ & $108 \pm 12$ & 0.0145 \\
\hline $\mathrm{D}_{\mathrm{L} C O} \%$ of predicted & $60 \pm 20$ & $84 \pm 22$ & $<0.0001$ \\
\hline $\mathrm{D}_{\mathrm{L}} \mathrm{CO} / \mathrm{V}_{\mathrm{A}}, \%$ predicted & $74 \pm 24$ & $98 \pm 26$ & $<0.0001$ \\
\hline $\mathrm{CRS}, \mathrm{units}$ & $0.71 \pm 0.06$ & $0.42 \pm 0.06$ & $<0.0001$ \\
\hline $\mathrm{PaO}{ }_{2}, \mathrm{mmHg}$ & $70 \pm 8$ & $72 \pm 8$ & 0.3239 \\
$\mathrm{PaCO}, \mathrm{mmHg}$ & $38 \pm 4$ & $39 \pm 5$ & 0.4456 \\
\hline
\end{tabular}

BMI, body mass index; $\mathrm{FEV}_{1}$, forced expiratory volume in $1 \mathrm{~s}$; VC, vital capacity; FRC, functional residual capacity; RV, residual volume; TLC, total lung capacity; $\mathrm{D}_{\mathrm{L}} \mathrm{CO}$, single-breath lung diffusion capacity; $\mathrm{V}_{\mathrm{A}}$, alveolar volume; $\mathrm{CRS}$, clinical and radiological score. Data are mean \pm standard deviation. P, significance levels by Student's unpaired t test or Chi-square test withYates' correction where appropriated. 
Table 2. Lung function data before and after bronchodilator.

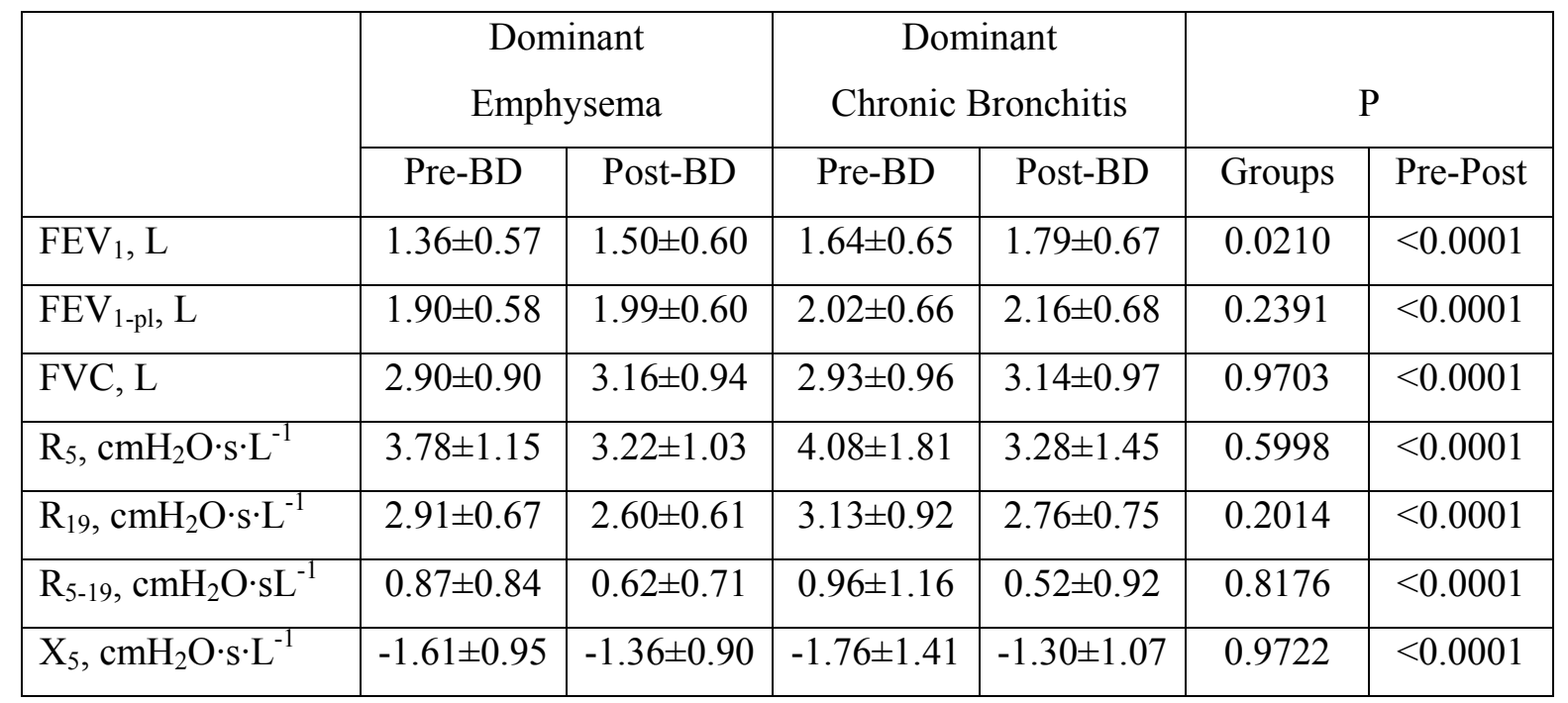

$\mathrm{BD}$, bronchodilator; $\mathrm{FEV}_{1-\mathrm{pl}}$, forced expiratory volume in $1 \mathrm{~s}$ measured in the body plethysmograph; $\mathrm{R}_{5}$ and $\mathrm{R}_{19}$, inspiratory resistance at 5 and $19 \mathrm{~Hz}$, respectively; $\mathrm{X}_{5}$, inspiratory reactance at $5 \mathrm{~Hz}$; Data are mean \pm standard deviation. $\mathrm{P}$, significance levels by two-factor repeated-measure ANOVA. 
Table 3. Spirometry quality control additional data and breathing pattern.

\begin{tabular}{|l|c|c|c|c|c|c|}
\hline \multirow{2}{*}{} & \multicolumn{2}{|c|}{ Dominant Emphysema } & \multicolumn{2}{c|}{$\begin{array}{c}\text { Dominant Chronic } \\
\text { Bronchitis }\end{array}$} & \multicolumn{2}{c|}{ P } \\
\cline { 2 - 7 } & Pre-BD & Post-BD & Pre-BD & Post-BD & Groups & Pre-Post \\
\hline PEFT, ms & $0.06 \pm 0.02$ & $0.06 \pm 0.02$ & $0.06 \pm 0.02$ & $0.06 \pm 0.02$ & 0.9291 & 0.8769 \\
\hline BEV, L & $0.05 \pm 0.02$ & $0.06 \pm 0.03$ & $0.06 \pm 0.03$ & $0.07 \pm 0.03$ & 0.3081 & 0.5416 \\
\hline BF, min $^{-1}$ & $16 \pm 4$ & $16 \pm 4$ & $16 \pm 4$ & $15 \pm 4$ & 0.6014 & 0.5416 \\
\hline$\dot{V}_{\mathrm{E}}, \mathrm{L} \cdot \mathrm{min}^{-1}$ & $15 \pm 5$ & $15 \pm 5$ & $13 \pm 4$ & $14 \pm 4$ & 0.1063 & 0.3492 \\
\hline
\end{tabular}

PEFT, time to peak flow; BEV, back extrapolation volume; $\mathrm{BF}$, breathing frequency; $\dot{\mathrm{V}}_{\mathrm{E}}$ minute ventilation. Data are mean \pm standard deviation. 
Table 4. Patient-centered variables.

\begin{tabular}{|c|c|c|c|}
\hline & $\begin{array}{c}\text { Dominant } \\
\text { Emphysema }\end{array}$ & $\begin{array}{c}\text { Dominant } \\
\text { Chronic Bronchitis }\end{array}$ & $\mathrm{P}$ \\
\hline MRC score, units & $2.4 \pm 0.9$ & $2.2 \pm 0.7$ & 0.2646 \\
\hline SGRQ & $33 \pm 21$ & $37 \pm 18$ & 0.4140 \\
Symptoms & $43 \pm 21$ & $42 \pm 19$ & 0.9145 \\
Activity & $23 \pm 16$ & $20 \pm 14$ & 0.2269 \\
Impact & $31 \pm 16$ & $30 \pm 14$ & 0.6096 \\
Total & & & 0.6939 \\
\hline 6MWD & $989 \pm 101$ & $480 \pm 110$ & 0.2802 \\
Meters & $92 \pm 18$ & $96 \pm 18$ & 0.5071 \\
\hline \% predicted & $1.2 \pm 0.8$ & $1.1 \pm 0.9$ & \\
\hline Exacerbations/yr, $\mathrm{n}$ & & & \\
\hline
\end{tabular}

MRC, Medical Research Council dyspnea score; SGRQ, Saint George's Respiratory Questionnaire; 6MWD, 6-minute walking distance. Data are mean \pm SD. P, significance levels by Student's unpaired $\mathrm{t}$ test. 